\title{
IDENTIFIKASI PATAHAN MANADO DENGAN MENGGUNAKAN METODE GEOLISTRIK KONFIGURASI HALF SCHLUMBERGER DI KOTA MANADO
}

\author{
Jeldy Manuho ${ }^{1)}$, As'ari ${ }^{1)}$, Guntur Pasau ${ }^{1)}$ \\ 1) Program Studi Fisika FMIPA, UNSRAT, MANADO \\ e-mail: Jmanuho@Gmail.com, as.ari2222@yahoo.co.id, Pasaujunior@Gmail.com
}

\begin{abstract}
ABSTRAK
Peta Geologi lembar Manado, Sulawesi Utara menunjukkan bahwa daerah penelitian yaitu jalan Ringroad kelurahan Malendeng kecamatan Paal II merupakan jalur yang dilalui oleh Patahan Manado, Untuk mendeteksi keberadaan Patahan digunakan metode Geolistrik Tahanan jenis dengan konfigurasi Half Schlumberger, dengan menggunakan 1 unit resistiviti meter GEPS 2000, diambil 1 Lintasan dengan 5 titik Pengukuran dengan panjang lintasan 200 meter. Pengolahan data dilakukan dengan menggunakan software IP2WIN, berdasarkan pengolahan dan analisa data diperoleh pergeseran bidang lemah, keras dan lemah pada struktur patahan dan diduga sebagai kekar tarik.
\end{abstract}

Kata Kunci : Half Schlumberger, Software IP2WIN, Patahan Manado.

\section{MANADO'S FAULT IDENTIFICATION BY USING GEOELECTRIC HALF SCHLUMBERGER CONFIGURATION AT MANADO}

\begin{abstract}
Geology map of Manado, North Celebes shows that research region at Ringroad Street, Malendeng Village Subdistrict Paal 2 is a track of Manado's Fault. In order to detect these Fault existence, geoelectrical resistivity method is applied in the manner of Half Schlumberger configuration, by using 1 unit resistivity meter GEPS 2000. One line with five point of measurement is taken in 200 meters long. Data processing is done by using IP2WIN software. By data processing and analysing are acquired a weak - strong - weak zone at Fault structure which is supposed as tensional Joint.
\end{abstract}

Keywords : Half Schlumberger, IP2WIN software, Manado's Fault

\section{PENDAHULUAN}

Patahan adalah struktur rekahan yang telah mengalami pergeseran dan umumnya disertai oleh struktur yang lain seperti lipatan dan rekahan, Noor (2009). untuk menentukan lokasi persis suatu patahan aktif di permukaan, tidak cukup hanya dari bentang alam dan geologi tetapi harus dibantu dengan survei geofisika bawah permukaan seperti dengan metode seismik refleksi resolusi tinggi, seismik refraksi, georadar, geolistrik dan metode lainnya, Natawidjaya (2007).

Salah satu metode geofisika yang sering digunakan dalam mengidentifikasi struktur bawah permukaan bumi terutama sesar / patahan adalah metode geolistrik. Metode ini, merupakan metode yang menggunakan prinsip aliran arus listrik dalam menyelidiki struktur bawah permukaan bumi. Minarto dan Astoro (2011) telah melakukan penelitian untuk mengidentifikasi struktur patahan bawah permukaan bumi pada eksplorasi panasbumi daerah Mataloko dengan menggunakan metode Geolistrik konfigurasi Half Schlumberger. Hasil penyelidikan menunjukkan adanya beberapa sesar, salah satunya diperkirakan sebagai Sesar Waeluja.

(Bakrun dkk. 2007) dengan menggunakan metode Half Schlumberger telah melakukan penyelidikan didaerah panas bumi MakaleSangala Kabupaten Tana Toraja, Propinsi Sulawesi Selatan untuk memetakan anomali tahanan jenis pada daerah prospek panas bumi. Metode yang digunakan dalam 
penelitian ini adalah metode geolistrik tahanan jenis konfigurasi Half Schlumberger, prinsip kerja metode ini adalah menginjeksikan arus listrik ke bawah permukaan bumi sehingga diperoleh beda potensial, yang kemudian akan didapat informasi mengenai tahanan jenis batuan. arus listrik mengalir didalam tanah melalui batuan-batuan dan sangat dipengaruhi oleh adanya air tanah. Metode geolistrik cukup sederhana, murah dan sangat rentan terhadap gangguan sehingga cocok digunakan dalam eksplorasi dangkal Ngadimin (2001) dalam (Rohim dkk. 2010).

Berdasarkan Peta geologi didaerah Sulawesi Utara terdapat Patahan Manado meskipun sudah teridentifikasi, akan tetapi hingga saat ini belum pernah dilakukan survei geofisika bawah permukaan untuk mengetahui lokasi atau posisi tepat Patahan Manado tersebut. Oleh karena itu penelitian dengan menggunakan metode geolistrik tahanan jenis konfigurasi Half Schlumberger ini diharapkan mampu memberikan informasi tentang resisitivitas batuan dan kondisi struktur bagian bawah permukaan di daerah penelitan sehingga nantinya akan dapat mengetahui lokasi atau posisi tepat Patahan Manado.

\section{METODE GEOLISTRIK TAHANAN JENIS KONFIGURASI HALF SCHLUMBEREGR}

\section{Aliran Listrik di dalam bumi}

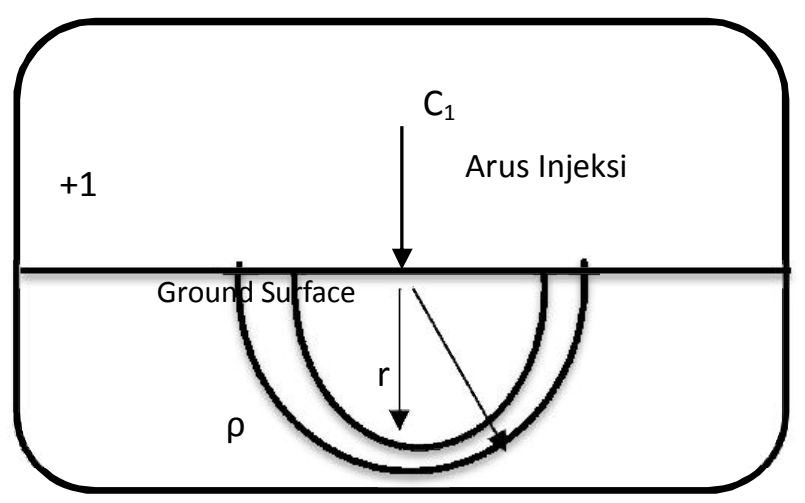

Gambar 1 Penampang vertikal ketika arus diinjeksikan pada permukaan yang sama

Diasumsikan bumi homogen, yang memiliki resistivitas $(\rho)$ yang sama, misalkan kemudian diinjeksikan arus $I$ pada titik $\mathrm{C}_{1}$, yang akan mengalir secara radial setengah bola di dalam bumi sehingga ekuipotensial akan di pusatkan di titik $\mathrm{C}_{1}$ ( Gambar 1) persamaan (1) dan (2) di daerah antara dua belahan titik yang konsentris pada jarak $r$ dan $r+d r$, potensial diantara jarak belahan bumi adalah :

$$
\begin{aligned}
& \rho=\frac{V A}{I L} \ldots \ldots \ldots \ldots . . . . \\
& -d V=\frac{I \rho}{2 \pi r^{2}} d r
\end{aligned}
$$

Dimana integrasi diberikan potensial $V$ pada jarak $r$ dari sumber arus sehingga :

$$
V=\frac{I \rho}{2 \pi r} \text {. }
$$

Jika ada dua elektroda arus dipermukan sumber $I$ di titik $\mathrm{C} 1$ dan $-I$ dititik $\mathrm{C} 2$ (Gambar 2) dan persamaan (3) memungkinkan jumlah distribusi potensial dari kombinasi sumber masukan ditemukan disetiap tempat.

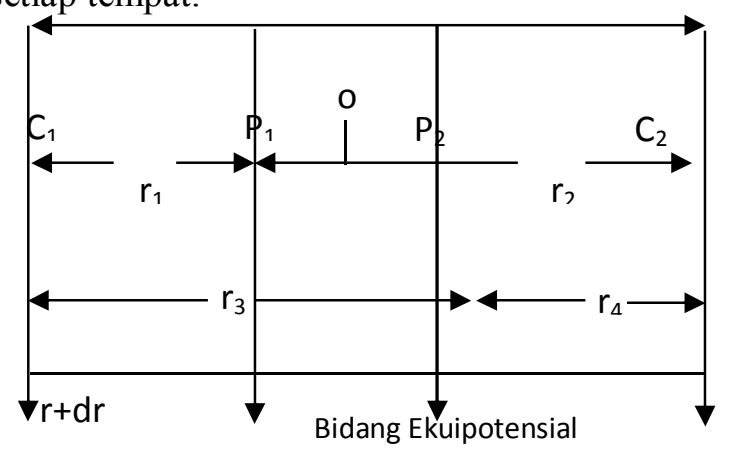

Gambar 2 Susunan Elektroda

Potensilal dititik P1 diberikan :

$$
V_{l}=\frac{I \rho}{2 \pi}\left(\frac{1}{r 1}-\frac{1}{r 2}\right)
$$

Potensial dititik P2 diberikan :

$$
V_{2}=\frac{I \rho}{2 \pi}\left(\frac{1}{r 3}-\frac{1}{r 4}\right)
$$

Potensial di antara P1 dan P2 kemudian menjadi :

$$
\Delta V=\frac{I \rho}{2 \pi}\left(\left(\frac{1}{r 1}-\frac{1}{r 2}\right)-\left(\frac{1}{r 3}-\frac{1}{r 4}\right)\right) .
$$

Sehingga diperoleh resistivitas $(\rho)$ ditulis :

$$
\rho=\frac{\Delta V}{I}\left[\frac{I \rho}{2 \pi}\left(\frac{1}{r 1}-\frac{1}{r 2}-\frac{1}{r 3}+\frac{1}{r 4}\right)\right]^{-1} . .
$$

dengan $K=\left[\frac{I}{2 \pi}\left(\frac{1}{r 1}-\frac{1}{r 2}-\frac{1}{r 3}+\frac{1}{r 4}\right)\right]^{-1}$... Persamaan $\frac{\Delta V}{I}$ sebagai resistansi di antara titik P1 dan persamaan dalam kurung sebagai faktor geometri $(K)$ yang nilainya bergantung pada posisi semua empat titik yaitu posisi elektroda dalam penelitian (Wuryantoro, 2007). 


\section{Konfigurasi Half Schlumberger}

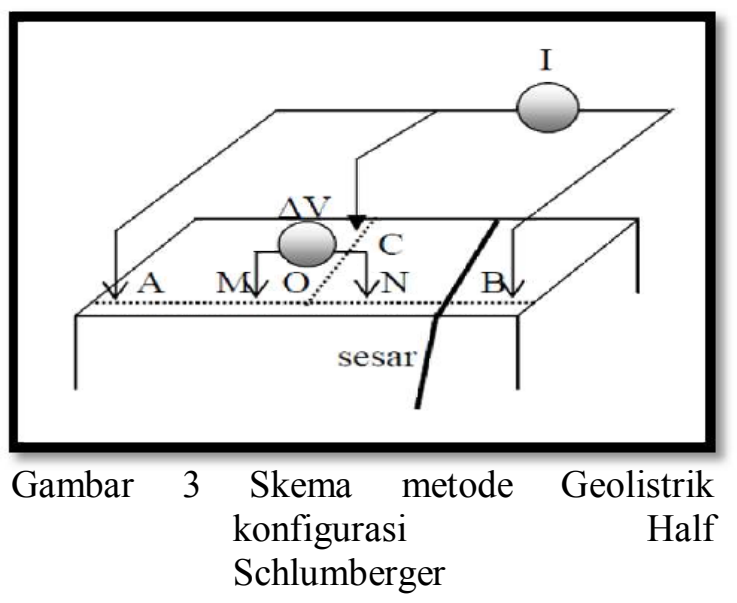

\begin{tabular}{lcr}
\multicolumn{1}{c}{ Konfigurasi } & $\begin{array}{r}\text { Head-on } \\
\text { bertujuan }\end{array}$ & (Half- \\
untuk \\
Schlumberger) & diskontinuitas & lateral, \\
mengidentifikasi & disk
\end{tabular} terutama sesar yang memiliki anomali konduktif lokal Minarto dan Astoro (2011) Konfigurasi elektroda seperti konfigurasi Schlumberger (AMNB) dengan menambahkan satu elektroda $C$ yang terletak sedemikian rupa hingga $\mathrm{OC}$ tegak lurus $\mathrm{AB}$ dan jarak $\mathrm{OC}$ lebih besar dari $\mathrm{AB}$.Arus diinjeksikan melalui elektroda $\mathrm{AC}$ atau $\mathrm{BC}$, dan pengukuran beda potensial dilakukan pada elektroda MN .

\section{METODE PENELITIAN}

\section{Desain Survei}

Pada penelitian ini, pengukuran dilakukan pada 1 lintasan yang terdiri dari 5 titik. Panjang 1 lintasan adalah $200 \mathrm{~m}$, berada pada koordinat $1^{\circ} 28^{\prime} 43.37^{\prime \prime} L U$ dan $124^{\circ} 53^{\prime} 31.26^{\prime \prime} \mathrm{BT}-1^{\circ} 28^{\prime} 48.06^{\prime \prime} L U$ dan $124^{\circ} 53^{\prime} 35.76^{\prime \prime} \mathrm{BT}$

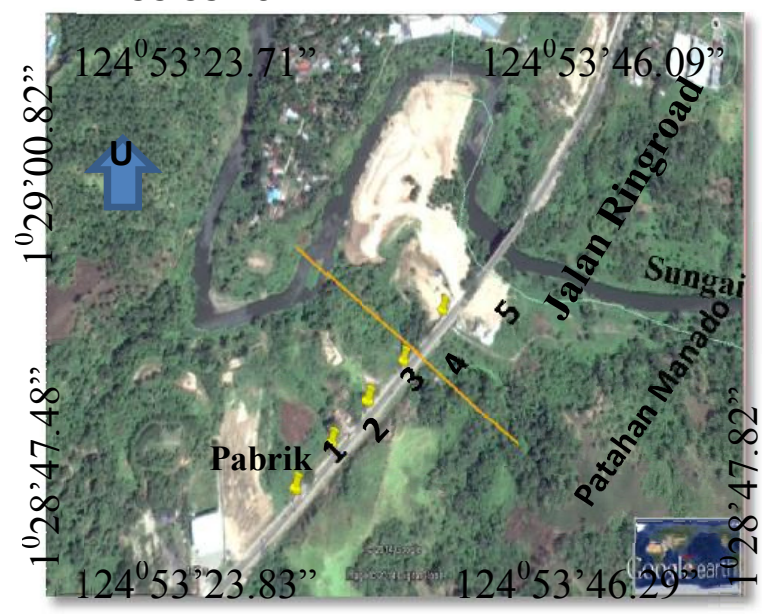

Gambar 4 Desain survei daerah penelitian

\section{Lokasi dan waktu}

Survei Geolistrik dilaksanakan di Jalan Ringroad, Kelurahan Malendeng, Kecamatan Paal II dengan menggunakan konfigurasi Half Schlumberger yang berlangsung dari bulan Agustus - Desember 2014. Pengolahan data kemudian dilaksanakan di Laboratorium Geofisika Jurusan Fisika FMIPA UNSRAT.

\section{Alat dan bahan \\ Alat yang digunakan dalam penelitian ini adalah, 1 unit resistiviti meter GEPS 2000, 1 unit GPS, HT, Software IP2WIN, Google Earth, software Surfer 8 Bahan yang digunakan dalam penelitian ini adalah peta geologi.}

\section{HASIL DAN PEMBAHASAN \\ Hasil Analisis Lintasan}

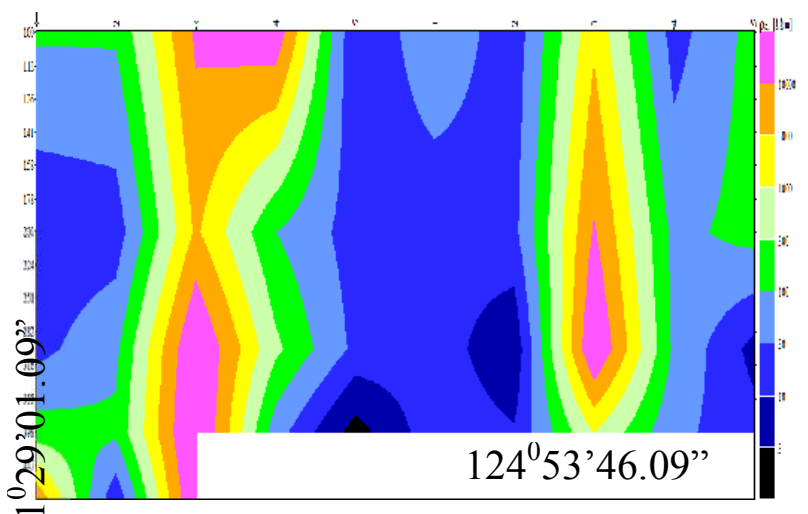

Gambar 5 Penampang Lintang kontur

$$
\begin{aligned}
& \text { Resistivitas pada titik sounding } \\
& 1-5
\end{aligned}
$$

Berdasarkan Gambar 5 Adanya bidang-bidang lemah yang ditunjukkan oleh warna biru dengan harga resistivitas rendah yang berkisar antara 3-100 $\Omega \mathrm{m}$, bidangbidang tersebut terletak pada titik 1, 2 dan 5 pada lintasan AOC, sedangkan untuk titik BOC bidang lemah terletak pada titik 1, 2 dan 4 dengan harga resistivitas 3-100 $\Omega \mathrm{m}$ yang ditunjukkan oleh warna biru. Bidang lemah ini terletak pada kedalaman 100- $400 \mathrm{~m}$, untuk masing-masing titik yang terdapat pada AOC dan BOC. Harga resistivitas yang tinggi terdapat pada titik 3 dan 4 Lintasan AOC dan titik 3 lintasan BOC dengan kisaran harga resistivitas $100-1000 \Omega \mathrm{m}$. Bidang lemah yang ditunjukkan oleh harga resistivitas yang lebih rendah dibandingkan lapisan- lapisan lainnya, diduga merupakan bidang rekahan karena lapisan pada titik-titik ini merupakan lapisan yang berongga hasil endapan 
reruntuhan dari atas permukaan yanng terjadi dalam kurun waktu yang lama dengan kata lain bahwa lapisan pada bidang lemah tersebut bukanlah lapisan dengan jenis batuan / tanah yang sebenarnya, sehingga lapisan terisi Fluida mengakibatkan terjadinya penurunan nilai resistivitas. Oleh karena itulah bidang lemah tersebut diduga merupakan bidang Rekahan.

Hasil Analisis Lintasan berdasarkan nilai Resistivitas rata-rata antara sisi AOC dan BOC.

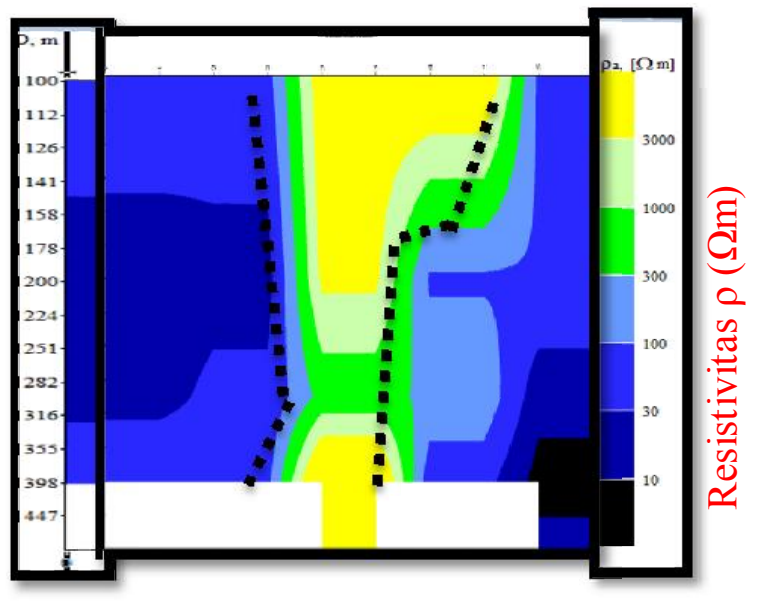

Berdasarkan Gambar dapat dilihat garis putus - putus yang berwarna hitam merupakan batas - batas kekar, pada titik 1, 2 , dan 5 merupakan lapisan yang didominasi oleh struktur batuan dengan nilai resistivitas rendah yang ditunjukkan oleh warna biru dengan harga resistivitas yang berkisar antara 10-30 $\Omega \mathrm{m}$ dan diduga merupakan kekar . Sedangkan lapisan tanah pada titik sounding 3 bersifat keras karena didominasi oleh struktur batuan yang memiliki nilai resistivitas yang tinggi. Pada titik sounding 4 dikedalaman $200 \mathrm{~m}$ dengan harga resistivitas 158 - 400 yang ditunjukkan oleh warna biru merupakan lapisan yang Lemah karena memiliki nilai resistivitas yang lebih rendah.

\section{KESIMPULAN}

1. Investigasi Patahan Manado dengan menggunakan metode geolistrik tahanan jenis konfigurasi Half Schlumberger di jalan Ringroad Kelurahan Malendeng, diperoleh perubahan keadaan bidang lapisan dari posisi semula yaitu terdapat bidang lemah, keras dan lemah pada struktur patahan dan diduga sebagai kekar Tarik.
2. Lapisan pada titik pengukuran 1,2 , dan 5 merupakan lapisan yang Lemah dan didominasi oleh struktur batuan dengan nilai resistivitas rendah yaitu $10-30$ $\Omega \mathrm{m}$ dan diinterpretasikan sebagai batuan Basalt dan Lempung, sedangkan untuk Lapisan pada titik Sounding 3 didominasi oleh struktur batuan dengan nilai resistivitas yang tinggi $300-3000 \Omega \mathrm{m}$ diinterpretasikan sebagai batuan garnit.

\section{SARAN}

Untuk mendapatkan hasil yang lebih baik, maka penulis menyarankan :Perlu dilakukan penelitian yang berkelanjutan dengan metode dan konfigurasi yang sama, dengan menambahkan titik ukur penelitian.

\section{DAFTAR PUSTAKA}

Bakrun, S.Widodo, dan M. Kholid. 2007. Survei Geolistrik dan Head-On di Daerah Panas Bumi Bonjol Kabupaten Pasaman, Sumatera Barat, Proceeding pemaparan Hasil Kegiatan Lapangan dan Non Lapangan Tahun 2007 pusat sumber daya geologi

Minarto, E., dan T. Astoro, 2011. Identifikasi Struktur sesar Bawah Permukaan dengan menggunakan Konfigurasi Half-Schlumberger (Head-on) pada eksplorasi panasbumi Daerah Mataloko. FMIPA ITS, Surabaya.

Natawidjaya, D. H., 2007. Evaluasi Bahaya Patahan Aktif, Tsunami dan Goncangan Gempa. Laboratorium Riset Bencana Alam GeoteknologiLIPI

Noor, D. 2009, Pengantar Geologi FMIPA ITS, Surabaya.

Rohim, N T., Heru S, Nunjil H. 2010. Aplikasi Metode Geolistrik Sounding dengan konfigurasi Pole-pole untuk mengukur Resistivitas Bawah permukaan tanah dan mengetahui struktur tanah.

Wuryantoro,. 2007. Aplikasi metode Geolistrik tahanan jenis untuk menentukan letak dan kedalaman aquifer air tanah (studi kasus di Desa Temperak kecamatan Sarang Kabupaten Rembang JawaTengah). 